Supplement of Geosci. Model Dev., 11, 4291-4316, 2018

https://doi.org/10.5194/gmd-11-4291-2018-supplement

(C) Author(s) 2018. This work is distributed under

the Creative Commons Attribution 4.0 License.

(c) (1)

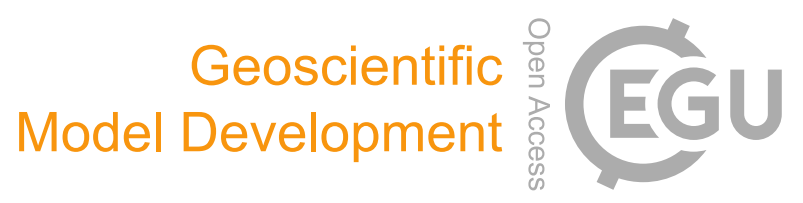

Supplement of

\title{
Dynamic hydrological discharge modelling for coupled climate model simulations of the last glacial cycle: the MPI-DynamicHD model version 3.0
}

Thomas Riddick et al.

Correspondence to: Thomas Riddick (thomas.riddick@ mpimet.mpg.de)

The copyright of individual parts of the supplement might differ from the CC BY 4.0 License. 


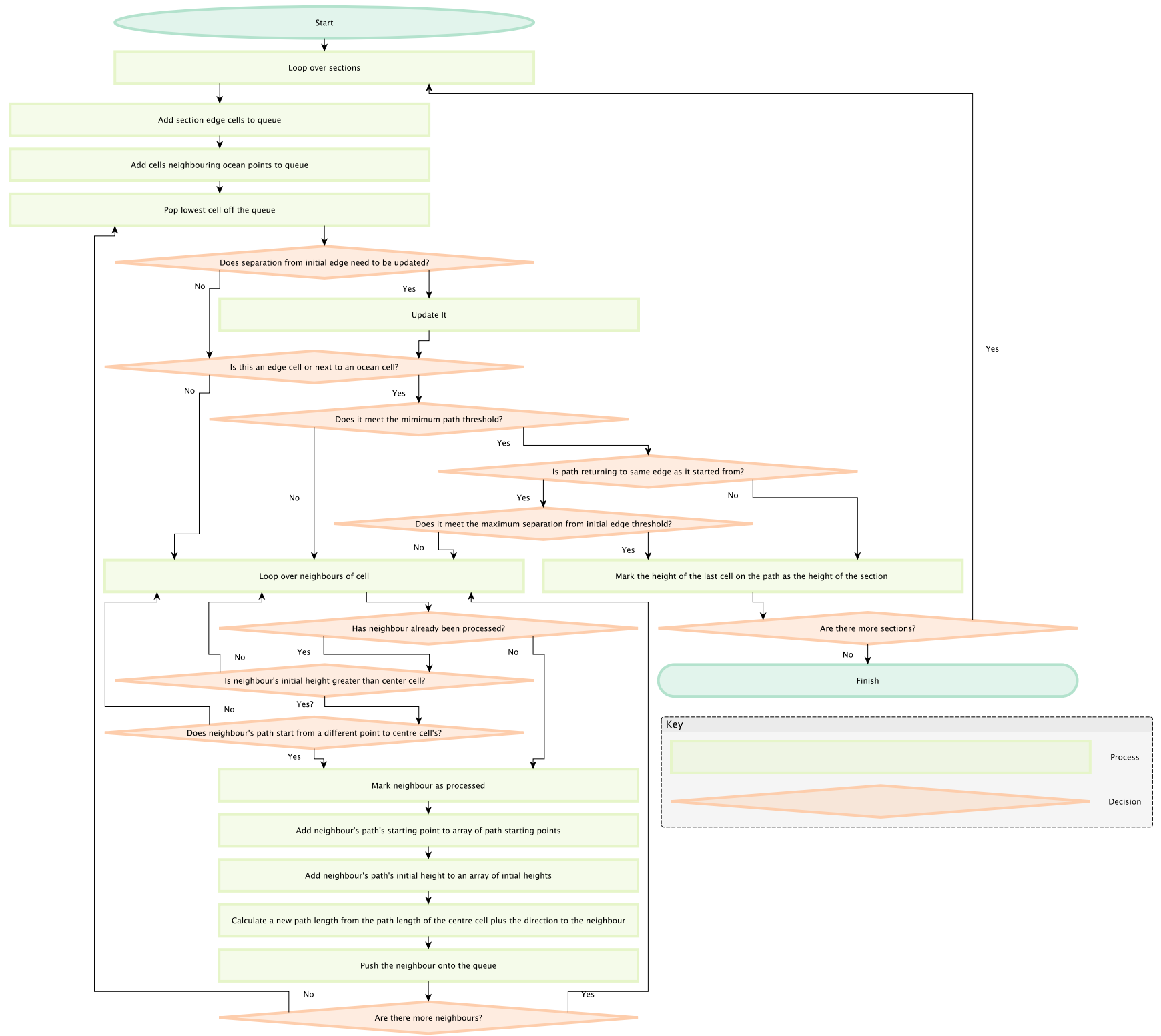

Figure S1. Flow diagram illustrating the steps of the orography upscaling algorithm. 